\title{
Lessons from the DeepWater Horizon debacle: a precautionary tale
}

\author{
Beth Beloff
}

Accepted: 14 June 2010/Published online: 2 July 2010

(C) Springer-Verlag 2010

It has been virtually impossible to avoid the images of death and destruction in the Gulf of Mexico-through all forms of media-since the April 20th explosion of BP's deepwater drilling platform, Deepwater Horizon-and the ensuing unimpeded gushing of oil from one mile under the sea. While there has been so much news coverage-both speculated and actual - of the events leading to that accident and its subsequent real and anticipated impacts, and an ongoing barrage of opinions about what this all means, I nonetheless felt obliged to navigate through the noise and make sense out of what the deeper meaning is in terms of sustainability.

We are now facing the worst environmental disaster of its kind in US history; the oil release to the Gulf is ongoing, with no clear end in sight, and it is threatening to be not only a significant environmental disaster but also a huge social and economic one for years to come. Among the costs (as of June 14):

- Eleven lives lost from the explosion;

- Up to 60,000 barrels of oil spilling per day, or an equivalent of one Exxon Valdez spill per week; further, to date an estimated 700,000 gallons of toxic dispersant have been released into the Gulf;

- Cleanup costs could end up at \$15-23 billion plus \$14 billion in claims (Credit Suisse);

- The coasts of Louisiana, Alabama, Mississippi, Florida, and potentially up the Atlantic coast of the US are impacted; Texas will be spared unless unexpected

B. Beloff

BRIDGES to Sustainability Institute, Houston, TX, USA

B. Beloff $(\bowtie)$

Beth Beloff \& Associates, Houston, TX, USA

e-mail: beth@bethbeloff.com events shift the currents to the west, thus upping the ante for measures that protect the natural environments along the coast of Texas as the last remaining "clean" coastal area in the US Gulf;

- Ecosystems are at risk: Birds and aquatic life in its path-from surface to deep water oil plumes - are all endangered, including sensitive estuaries, endangered species, newly found deep sea coral reefs and their dependents, some of which are yet unknown species, and so on;

- Communities are at risk: Economic development and community social sustainability, supported by the fishing and tourism industries, are being severely impacted; further, the offshore oil industry has been placed on hold in large part, impacting southern towns-workers and commercial operations that support that industry;

- Political impacts are also significant: some offshore drilling activities have been halted or states are considering halting future offshore developments; there are efforts in Congress to raise the cap on offshore drilling liabilities; agencies that oversee offshore drilling are being criticized and reorganized; President Obama's leadership is being challenged by his handling of the spill; relations with Britain are potentially being strained by the perceived attacks on its most significant corporation;

- BP, heretofore the fourth largest corporation in the world, has lost nearly half of its market capitalization since April, with bonds trading at junk levels (according the NYT); not only is there growing public anger toward BP and reputational damage, but the US government is considering criminal actions against BP. This could affect the financial health of a bedrock British corporation on which many stakeholders depend. 
The impacts associated with an offshore drilling blowout at these depths were clearly enormous, although the risk of a catastrophic failure, as well as the inability to stop the leak, appeared unlikely.

In 2005, David Eyton, then VP for BP's deepwater developments in the Gulf, spoke prophetically (as reported by Elizabeth Rosenthal in the NYT Our Fix-it Faith and the Oil Spill, 5-28-10): "If we've learned anything so far about the deepwater Gulf of Mexico, it is that it contains surprises. And that means an operator needs depth-depth in terms of resources and expertise-to create the capability to respond to the unexpected." Mr. Eyton went on to say that he was optimistic that both BP's risk management expertise coupled with its new technologies would play a major role in allowing the company to overcome potential obstacles of nature. The "Precautionary Principle"-a bedrock principle of sustainable development-postulates that if an action has the potential of causing great risk to the community or to the environment, and in the absence of scientific consensus on the harmfulness of the action or how to mitigate it, it is up to those taking the action to ensure that they do no harm. Did BP, and indeed, does the oil industry in general, ensure that they have reduced those risks by creating the "capability to respond to the unexpected"- - to those catastrophic events that could change the face of a region-environmentally, socially and economically-for years to come? Or did BP have misplaced confidence in technology to overcome the forces of nature in both preventing the blowout in the first place and then in plugging the hole that was created by it? As is now evident, the failures were both technological and human.

We hold the belief that technology will solve all of our problems. Yet is seems that the challenges of deepwater oil exploration have exceeded our knowledge of how to do so safely at those depths and under those pressures. The evidence rests in the fact that, after close to 8 weeks of searching for solutions, oil is still spewing from the floor of the Gulf. No viable contingency plan for plugging a blowout existed. From my reading of the accounts, it appears that the Deepwater Horizon operators were under pressure to cut corners in time and expense in developing and capping the well, ignoring concerns about the risks involved regarding a blowout.

The government also had a role to play. It was to ensure that proper engineering practices were followed and that there were effective contingency plans to reduce risks to the public and the environment; however, there was too much dependence on BP taking responsibility for its own safety practices, engineering and technology decisions, and accurately measuring oil flows and managing the disaster response effectively.

BP has a history of serious safety violations, thus appearing to place profits over the environment and safety.
BP pleaded guilty to violating the Clean Air Act by failing to provide a safe facility after the 2005 explosion at its Texas City refinery that killed 15 workers. It also pleaded guilty to violating the Clean Water Act by failing to properly maintain its pipelines, causing oil spills in 2006 in Alaska's Prudhoe Bay. The company went from the darling of the sustainability movement, and one in which "beyond petroleum" seemed to reflect environmental leadership, to one whose clear lack of a safety culture made it suspect in other areas of social responsibility. With an attitude elevating profits over safety and risk, and with pressure to go farther out and drill deeper to extract oil, in hindsight it should not be surprising that this catastrophe occurred.

Does responsibility for this catastrophe in the Gulf stop with BP (and perhaps Transocean and Halliburton) or the regulators for not providing sufficient oversight? I argue that it should not stop there. We all bear some personal responsibility. It is our addiction to oil that causes many of the consequences evident today and which encourage oil companies to explore farther, faster and deeper than perhaps their technologies can take them to satisfy our unsustainable demands. Our blind faith in technology lulls us into believing that technology will create safe solutions on which we can all depend. But all technologies, whether "clean" or not, have limitations and unintended consequences. We must do a better job assessing environmental and social consequences of our use of technology before those technologies are put in place. Even if the short-term risks seem exceedingly remote, those risks should be realistically and substantially factored in. Further, if the people who make decisions about the development, use, and management of those technologies are not encouraged and rewarded for their depth in ethics and infused with a sense of responsibility that public and environmental safety must come first - the real human factor-we will continue to be helpless onlookers to witness grieving oil worker widows, lifeless pelicans covered in oil, pristine Gulf coast beaches covered with tar, and our nation in shock that "Beyond Patience" cannot find a solution to the continuing environmental, economic and social disaster.

It is incumbent on us to use this unfolding disaster in the Gulf of Mexico as a major wake-up call. As with many of the environmental laws enacted in the US that were responses to specific crises that captured our national indignation-the Clean Water Act and Superfund, as prominent examples-we should take this opportunity to craft more rational policies that prevent such oil disasters in the future. Further, as consumers of $20 \%$ of the world's oil, but with less than $2 \%$ of its reserves, accessed increasingly in environmentally sensitive areas, we must find more rational comprehensive clean energy and climate policies. We are seeing tangible and tragic evidence of the cost of our addiction to oil, and that cost is getting too great. 


\section{Author Biography}

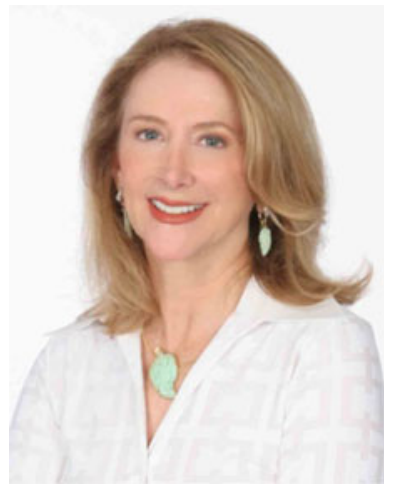

Beth Beloff has spent 20 years as a thought leader in formulating the concepts and practice of sustainable development. She is an expert in integrating sustainable development with other critical aspects of business performance. She is Founder and Principal of Beth Beloff \& Associates, a sustainability consulting company specializing in developing sustainability strategies, assessment methodologies, and sustainability performance measures. She is also President of the sustainability non-profit organization, BRIDGES to Sustainability Institute (formerly BRIDGES to Sustainability), which she founded in 1997. For over 10 years, BRIDGES has developed innovative approaches to support decision making with respect to sustainability. In 2005, Golder Associates, a geotechnical and environmental services company, acquired the intellectual property of BRIDGES to Sustainability, and invited its team to join the firm. For several years Beth developed and directed the US sustainability practice of Golder Associates, while refreshing the vision of BRIDGES to Sustainability Institute. 